10 years ESJ

Special edition

\title{
Evaluation of Ischemic Heart Disease in the Young Population of Georgia
}

\author{
Gogishvili Giorgi, MD, PhD Student
}

David Aghmashenebeli University of Georgia, Georgia.

Medical Director, St.John The Merciful Private Clinic, Tbilisi, Georgia

Doi: $10.19044 /$ esj.2021.v17n18p33

Submitted: 02 November 2020

Accepted: 18 January 2021

Published: 01 June 2021
Copyright 2021 Author(s)

Under Creative Commons BY-NC-ND

4.0 OPEN ACCESS

Cite As:

Giorgi G. (2021). Evaluation of Ischemic Heart Disease in the Young Population of Georgia. European Scientific Journal, ESJ, 17(18), 33. https://doi.org/10.19044/esj.2021.v17n18p33

Abstract

Objective: Study of risk factors (RF) for ischemic heart disease (IHD) in young people is a significant problem in cardiology. Aims: Study and prognosis of ischemic heart disease in Georgian population under 45 years of age. Methods: The study included 107 young patients with coronary heart disease (from 18 to 44 years old), who were treated in the cardiology department of the St. John the Merciful Private Clinic. The average age was $(34.68 \pm 6.2)$ years. The control group consisted of 199 healthy volunteers without cardiovascular diseases at the age from 18 to 44 years, the average age was $(35.9 \pm 5.2)$ years. In all patients, traditional risk factors were assessed. Results: Regression analysis has shown that it increases the risk of ischemic heart disease:

- living in the city - OR=6.90(95\%CI:1.28-37.18);

- sleep disturbance - $\mathrm{OR}=45.62(95 \% \mathrm{CI}: 3.52-590.64)$;

- obesity -OR=24.56(95\%CI:4.14-145.66);

- hypertension - OR=40.76(95\%CI:8.07-205.92);

- excess intake of saturated fats - OR=79.94(95\%CI:10.93-584.43);

- night shift - OR=39.01(95\%CI:3.75-405.75);

- early detection of ischemic disease in grade I-II relatives $\mathrm{OR}=44.22(95 \% \mathrm{CI}: 8.07-242.17)$

- decrease - female gender - OR=0.14 (95\%CI:0.03-0.70) and married $\mathrm{OR}=0.01(95 \% \mathrm{CI}: 0.00-0.08)$; 
Conclusion: The ability to predict the risk of developing IHD in young people on the basis of traditional RFs, most of which are modifiable, as well as the study of "new" RFs opens up new perspectives in the formation of a strategic approach to the management of young patients in the presence of high risk.

Keywords: Young adults, IHD, risk factors

\section{Introduction}

Patients in whom ischemic heart disease (IHD) manifests itself at a young age differs from the elderly in the structure of risk factors (RF), clinical manifestations, and prognosis of the disease. Recently, in addition to the traditional RFs for the development of IHD, a wider range of signs associated with the early development of acute coronary syndrome has been considered [Ponomarenko IV. et al. 2019]. According to a number of foreign authors, the incidence of acute myocardial infarction among young patients varies from 2 to $10 \%$ [Morillas P., et al. 2007]. at a young age, collateral circulation is poorly developed, which complicates the outcome of the disease[Chigogidze, M., et al. 2020].

Whereas cardiovascular disease (CVD) metrics define risk in individuals above age 40 years, the earliest lesions of CVD appear well before this age. Despite the role of metabolism in CVD antecedents, studies in younger, biracial populations to define precise metabolic risk phenotypes are lacking[Murthy, V. L., et al. 2020]. In young patients, AMI often develops against the background of diabetes mellitus (DM) [Popov S.V., et al. 2020].

Proposes that psychosocial factors, such as stress, hypertension or depression, might be associated with the development and progress of CVD, which are independent of other identified psychosocial risk factors [Gilbert-Ouimet, M., et al. 2016].

The most prevalent psychosocial risk factors for CVDs identified were hypertension, stress, social support, depression, anxiety, physical inactivity and low socioeconomic status. Smoking, obesity, family history, quality of life and inappropriate sleep patterns were also considered among the risk factors[Saleem, M., et al.,2020].

We studied the role of genetic predisposition in the development of cardiovascular disease in the Georgian population under 45 years of age. In 19 (21.6\%) patients, early detection of ischemic heart disease (under 45 years of age) IHD was observed in first degree relatives[Gogishvili G, et al.2020].

Aims: Study and prognosis of ischemic heart disease in Georgian population under 45 years of age.

Methods: The study included 107 young patients with coronary heart disease (from 18 to 44 years old), who were treated in the cardiology department of the St. John the Merciful Private Clinic. The average age was 
(34.68 \pm 6.2$)$ years. The control group consisted of 199 healthy volunteers without cardiovascular diseases at the age from 18 to 44 years, the average age was $(35.9 \pm 5.2)$ years. In all patients, traditional risk factors were assessed, standard general clinical and biochemical studies were carried out to determine the parameters of lipid metabolism, fasting glucose levels, height and weight were measured with the calculation of body mass index. Patients with IHD underwent electrocardiography, echocardiography.

Statistical analysis: Continuous variables are expressed as mean $\pm \mathrm{SD}$, and categorical variables as frequencies and \%. Continuous variables were compared with the use of the two-tailed independent t test and Levene's test of equality of variance. Categorical variables with the use of the Fisher's exact test. Odds ratio - by logistic regression. $\mathrm{p}$ value $<0.05$ was considered as statistically significant.

All statistical analyses were performed using SPSS version 23.

Results: The distribution of patients according to the age of onset of ischemic heart disease is given in figure 1 . As we can see, the disease can be detected at an early age.

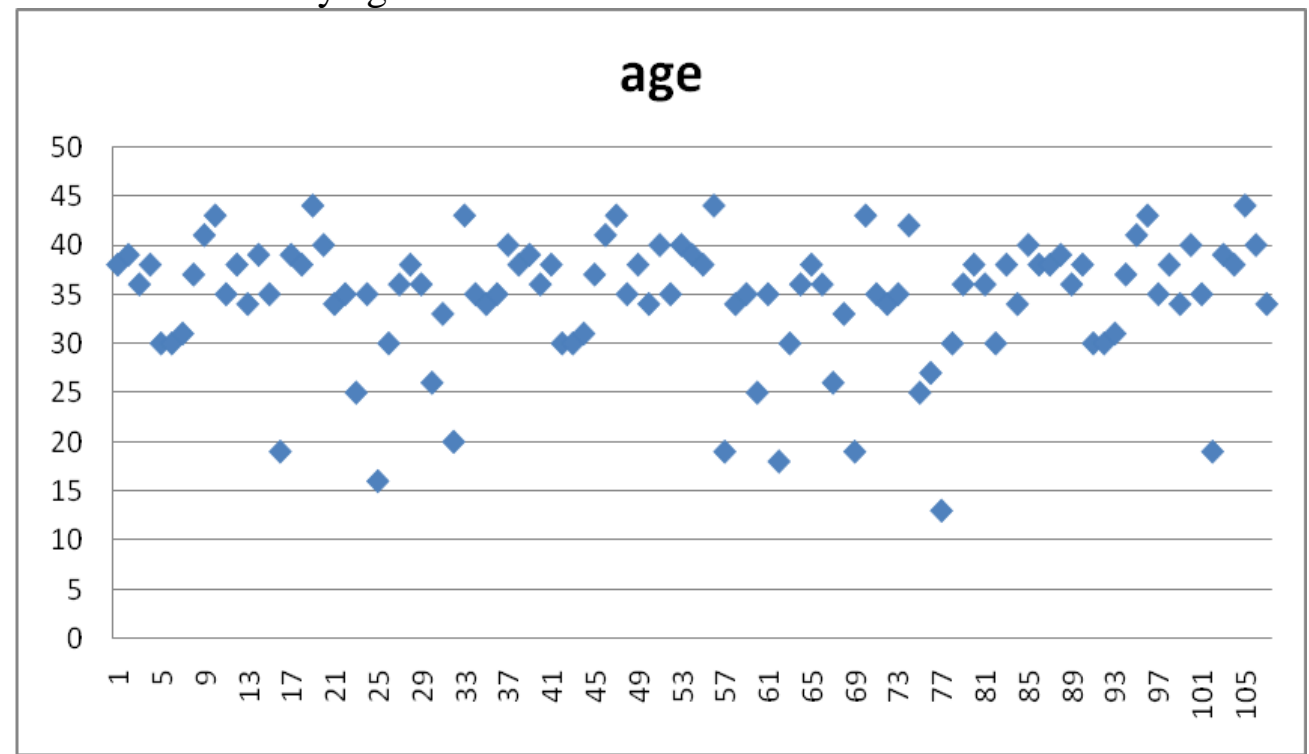

Fig.1: A comparison of the initial characteristics of young patients with healthy individuals of the same age is given in Table 1.

Table 1: Evaluation of factors affecting the patient between individuals with ischemic heart disease and the control group

\begin{tabular}{|c|c|c|c|c|c|}
\hline \multirow{2}{*}{} & & $\begin{array}{c}\text { Ischemic } \\
\text { heart disease } \\
\mathrm{N}=107\end{array}$ & $\begin{array}{c}\text { without } \\
\text { ischemic } \\
\text { heart disease } \\
\mathrm{N}=199\end{array}$ & \multirow{2}{*}{$\mathrm{F}$} & \multirow{2}{*}{$\mathrm{p}$} \\
\cline { 3 - 5 } & & $\mathrm{n}(\%)$ & $\mathrm{n}(\%)$ & \\
\hline Gender & Female & $12(11.21)$ & $101(50.75)$ & 61.68 & $<0.0001$ \\
\cline { 2 - 5 } & Male & $95(88.79)$ & $98(49.25)$ & 54.76 & $<0.0001$ \\
\hline
\end{tabular}




\begin{tabular}{|c|c|c|c|c|c|}
\hline \multirow[t]{6}{*}{ Bad habits } & $\begin{array}{c}\text { Frequent consumption of } \\
\text { alcohol }\end{array}$ & $42(39.25)$ & $63(31.66)$ & 1.78 & 0.1833 \\
\hline & Smoking & $63(58.88)$ & $119(59.80)$ & 0.02 & 0.8762 \\
\hline & Hypodynamics & $51(47.66)$ & $57(28.64)$ & 11.36 & 0.0008 \\
\hline & $\begin{array}{l}\text { Excess intake of saturated } \\
\text { fats }\end{array}$ & $52(48.60)$ & $50(25.13)$ & 18.16 & $<0.0001$ \\
\hline & Sleep disturbance & $19(17.76)$ & $3(1.51)$ & 30.06 & $<0.0001$ \\
\hline & Healthy eating regime & $12(11.21)$ & $90(45.23)$ & 40.82 & $<0.0001$ \\
\hline Living & City & $41(38.32)$ & $25(12.56)$ & 29.76 & $<0.0001$ \\
\hline \multirow{10}{*}{ Comorbid } & Obesity & $56(52.34)$ & $31(15.58)$ & 54.07 & $<0.0001$ \\
\hline & Dyslipidemia & $45(42.06)$ & $58(29.15)$ & 5.25 & 0.0226 \\
\hline & Gastrointestinal tract & $8(7.48)$ & $22(11.06)$ & 1.004 & 0.3170 \\
\hline & Thyroid gland & $4(3.74)$ & $12(6.03)$ & 0.73 & 0.3921 \\
\hline & Kidney disease & $2(1.87)$ & $0(0.00)$ & 3.77 & 0.0532 \\
\hline & Respiratory diseases & $10(9.35)$ & $24(12.06)$ & 0.52 & 0.4728 \\
\hline & Hypertension & $70(65.42)$ & $26(13.07)$ & 123.87 & $<0.0001$ \\
\hline & Diabetes mellitus & $12(11.21)$ & $11(5.53)$ & 3.25 & 0.0724 \\
\hline & Neurological disorders & $19(17.76)$ & $6(3.02)$ & 21.44 & $<0.0001$ \\
\hline & Chronic infections & $21(19.63)$ & $15(7.54)$ & 10.05 & 0.0017 \\
\hline \multirow{5}{*}{$\begin{array}{l}\text { Socio- } \\
\text { economic } \\
\text { factors }\end{array}$} & Unmarried & $88(82.24)$ & $34(17.09)$ & 204.96 & $<0.0001$ \\
\hline & Divorced or widowed & $17(15.89)$ & $64(32.16)$ & 9.71 & 0.0020 \\
\hline & In marriage & $2(1.87)$ & $101(50.75)$ & 97.78 & $<0.0001$ \\
\hline & $\begin{array}{l}\text { Unsatisfactory economic } \\
\text { conditions }\end{array}$ & $5(4.67)$ & $40(20.10)$ & 13.71 & 0.0003 \\
\hline & Unemployed & $21(19.63)$ & $11(5.53)$ & 15.42 & $<0.0001$ \\
\hline \multirow[t]{2}{*}{$\begin{array}{l}\text { living } \\
\text { environment }\end{array}$} & $\begin{array}{c}\text { Living near a harmful } \\
\text { enterprise }\end{array}$ & $5(4.67)$ & $0(0.00)$ & 9.69 & 0.0020 \\
\hline & $\begin{array}{l}\text { Living near a high voltage } \\
\text { transmitter, TV or telephone } \\
\text { tower }\end{array}$ & $10(9.35)$ & $8(4.02)$ & 3.58 & 0.0593 \\
\hline \multirow{8}{*}{$\begin{array}{c}\text { Working } \\
\text { Conditions }\end{array}$} & Industrial dust & $5(4.67)$ & $4(2.01)$ & 1.73 & 0.1898 \\
\hline & Vibration & $37(34.58)$ & $9(4.52)$ & 58.27 & $<0.0001$ \\
\hline & Industrial poisons & $6(5.61)$ & $8(4.02)$ & 0.40 & 0.5278 \\
\hline & Stressful work & $39(36.45)$ & $5(2.51)$ & 82.14 & $<0.0001$ \\
\hline & Impact of ionizing radiation & $4(3.74)$ & $18(9.05)$ & 2.95 & 0.0871 \\
\hline & Night shift & $21(19.63)$ & $5(2.51)$ & 28.48 & $<0.0001$ \\
\hline & Electromagnetic radiation & $21(19.63)$ & $4(2.01)$ & 31.56 & $<0.0001$ \\
\hline & Hard physical work & $21(19.63)$ & $7(3.52)$ & 23.23 & $<0.0001$ \\
\hline $\begin{array}{l}\text { Genetic } \\
\text { load }\end{array}$ & $\begin{array}{c}\text { Early detection of ischemic } \\
\text { disease in I-II degree } \\
\text { relatives } \\
\end{array}$ & $59(55.14)$ & $7(3.52)$ & 169.69 & $<0.0001$ \\
\hline
\end{tabular}

Statistical analysis provided an assessment of the factors affecting the patient between individuals with ischemic heart disease and the control group show us the incidence of the following factors is reliably high in the ischemic 
heart disease group: male, living in the city, living near a harmful enterprise, unmarried, unemployed. Obesity, dyslipidemia, hypertension, neurology disorders, chronic infections are reliably high among comorbidity. High frequency among work factors - hard physical work, vibration, night shift, electromagnetic radiation, stressful work. hypodynamics, excess intake of saturated fats, sleep disturbance are reliably high among bad habits. The genetic factor (early detection of ischemic i degree relatives) is characterized by a reliably high frequency.

The frequencies of the factors: unsatisfactory economic conditions, in marriage and divorced or widowed - are satisfactory high in the control group.

By regression analysis, we determined the risk factors and odds ratio of developing IHD at a young age (Table 2):

Table 2: Odds ratio of developing IHD at a young age

\begin{tabular}{|c|c|c|c|c|}
\hline & $\mathrm{p}$ & OR & \multicolumn{2}{|c|}{$95 \%$ C.I.for OR } \\
\hline Female gender & 0.0170 & 0.14 & 0.03 & 0.70 \\
\hline Married & $<0.0001$ & 0.01 & 0.00 & 0.08 \\
\hline Living in the city & 0.0250 & 6.90 & 1.28 & 37.18 \\
\hline Sleep disturbance & 0.0030 & 45.62 & 3.52 & 590.64 \\
\hline Obesity & $<0.0001$ & 24.56 & 4.14 & 145.66 \\
\hline Hypertension & $<0.0001$ & 40.76 & 8.07 & 205.92 \\
\hline $\begin{array}{c}\text { Excess intake of } \\
\text { saturated fats }\end{array}$ & $<0.0001$ & 79.94 & 10.93 & 584.43 \\
\hline Night shift & $<0.0001$ & 39.01 & 3.75 & 405.75 \\
\hline $\begin{array}{c}\text { Early detection of } \\
\text { ischemic disease in } \\
\text { grade I-II relatives }\end{array}$ & $<0.0001$ & 44.22 & 8.07 & 242.17 \\
\hline Constant & $<0.0001$ & 0.00 & & \\
\hline
\end{tabular}

Regression analysis has shown that it increases the risk of ischemic heart disease: living in the city, sleep disorders, overweight, Excess intake of saturated fats, hypertension, genetic factors, stress, and from working conditions - night shifts.

Regression coefficients: female gender $-\mathrm{B}=-1.94 \pm 0.81$; married $-\mathrm{B}=-$ $4.69 \pm 1.08$; living in the city $-\mathrm{B}=1.93 \pm 0.86$; sleep disturbance $-\mathrm{B}=3.82 \pm 1.31$; obesity - $\mathrm{B}=3.20 \pm 0.91$; hypertension - $\mathrm{B}=3.71 \pm 0.83$; excess intake of saturated fats $-\mathrm{B}=4.38 \pm 1.02$; night shift $-\mathrm{B}=3.66 \pm 1.20$; early detection of ischemic disease in grade $\mathrm{I}-\mathrm{II}$ relatives $-\mathrm{B}=3.79 \pm 0.87$. constant $=-13.65+3.13$ The risk assessment can be as follows:

Prediction can be made using the logistic regression equation, which has the following form:

$$
\begin{aligned}
& \mathrm{Z}=-13.65-1.94 * \mathrm{X} 1-4.69 * \mathrm{X} 2+1.93 * \mathrm{X} 3+3.82 * \mathrm{X} 4+3.20 * \mathrm{X} 5+3.71 * \mathrm{X} 6 \\
& +4.38 * \mathrm{X} 7+3.66 * \mathrm{X} 8+3.79 * \mathrm{X} 9(1)
\end{aligned}
$$


Where $\mathrm{X}$ is the value of the factor equal to 1 or $0, \mathrm{P}$ is the probability of developing the disease. To predict the outcome of treatment, determine the presence of a prognostic factor, if the subject has a prognostic sign, we put 1 in the regression equation, if not - 0 . We add the results and put them in formula (2):

$$
\mathrm{P}=1 / 1+\mathrm{e}^{-\mathrm{z}}
$$

As a result, we get the probability of developing coronary heart disease for a particular patient in accordance with his prognostic characteristics.

\section{Discussion}

In a large and longitudinal cohort study involving more than 2.5 million young adults, Kim SM, et al. found that early-onset diabetes and prediabetes increased the CVD incidence and all-cause mortality risk after the 10 year follow-up period. Furthermore, early recovery of hyperglycemia could reduce the subsequent 10 year CVD risk and all-cause mortality [Kim SM, et al. 2020]. According to this study, the incidence of diabetes is higher in the CHD group compared to the control group, although this difference is not statistically significant.

The findings of this study indicate that increased cholesterol levels were associated with high CVD risk in young adults. Furthermore, young adults with decreased cholesterol levels had reduced risk for CVD[Jeong, S. M., et al. 2018]. According to this paper, Excess intake of saturated fats is a risk factor for IHD.

According to some studies, Tobacco smoking is an important independent risk factor for acute myocardial infarction in young adults[Hbejan, K. et al. 2011], with similar strength of association for both genders. According to this study, this factor is not reliably different from control during IHD.

Nonoptimal levels of LDL and HDL cholesterol during young adulthood are independently associated with coronary atherosclerosis 2 decades later [Pletcher, M. J., et al., 2020]. A high prevalence of CVD risk factors was evident at a young age among Indians compared with high and upper middle income countries, with rural rates catching up with urban estimates[Vasan, S. K., et al. 2020].

Premature coronary artery disease is characterized by an unfavorable lipid profile [Pineda J. et al.2009;]. According to research, dyslipidemia is characterized by a reliably high frequency.

Evidence was found for a relationship between IHD and effort-reward imbalance, injustice, job insecurity, or long working hours. [Eller, N. H., et al. 2007]. This article shows that the frequency of employment characteristics in the IHD group is reliably high, night shift while increasing the risk of IHD. 


\section{Conclusion}

The ability to predict the risk of developing IHD in young people on the basis of traditional RFs, most of which are modifiable, as well as the study of "new" RFs opens up new perspectives in the formation of a strategic approach to the management of young patients in the presence of high risk.

\section{References:}

1. Chigogidze, M., Sharashidze, N., Pagava, Z., \&Taboridze, I. (2020). The Correlation of Collateral Circulation and Age during Acute Ischemic Heart Disease. European Scientific Journal, ESJ, 16(18), 335.

2. Eller, N. H., Netterstrøm, B., Gyntelberg, F., Kristensen, T. S., Nielsen, F., Steptoe, A., \& Theorell, T. (2009). Work-related psychosocial factors and the development of ischemic heart disease: a systematic review. Cardiology in review, 17(2), 83-97.

3. Gilbert-Ouimet, M., Trudel, X., Brisson, C., Milot, A., \&Vezina, M. (2014). Adverse effects of psychosocial work factors on blood pressure: systematic review of studies on demand-control-support and effort-reward imbalance models. Scandinavian journal of work, environment \& health, 109-132.

4. Gogishvili G, Petriashvili Sh, Nanobashvili N, Megrelishvili N, Taboridze I (2020). Association of blood group AB0 with coronary artery disease in young adults in georgian population. The First International Scientific - Practical Virtual Conference "Science and Technology in Modern Society: Problems, Prognoses and Solutions." 133-137.

5. Hbejan, K. (2011). Smoking effect on ischemic heart disease in young patients. Heart views: the official journal of the Gulf Heart Association, 12(1), 1.

6. Jeong, S. M., Choi, S., Kim, K., Kim, S. M., Lee, G., Park, S. Y., Kim, Y. Y., Son, J. S., Yun, J. M., \& Park, S. M. (2018). Effect of Change in Total Cholesterol Levels on Cardiovascular Disease Among Young Adults. Journal of the American Heart Association, 7(12), e008819.

7. Kim SM, Lee G, Choi S, Kim K, Jeong SM, Son JS, Y un JM, Kim SG, Hwang SS, Park SY, Kim YY, Park SM.( 2020) Association of earlyonset diabetes, prediabetes and early glycaemic recovery with the risk of all-cause and cardiovascular mortality. Diabetologia. Nov;63(11):2305-2314.

8. Morillas P., Bertomeu V., Pabón P. Characteristics and outcome of acute myocardial infarction in young patients. (2007)The PRIAMHO II study. Cardiology.; 107: 217-225. 
9. Murthy, V. L., Reis, J. P., Pico, A. R., Kitchen, R., Lima, J. A., LloydJones, D., ... \& Vasan, R. S. (2020). Comprehensive Metabolic Phenotyping Refines Cardiovascular Risk in Young Adults. Circulation.

10. Pineda J, Marín F, Marco P, et al. (2009)Premature coronary artery disease in young (age < 45) subjects: interactions of lipid profile, thrombophilic and haemostatic markers. Int J Cardiol. ;136:222-5.

11. Pletcher, M. J., Bibbins-Domingo, K., Liu, K., Sidney, S., Lin, F., Vittinghoff, E., \&Hulley, S. B. (2010). Nonoptimal lipids commonly present in young adults and coronary calcium later in life: the CARDIA (Coronary Artery Risk Development in Young Adults) study. Annals of Internal Medicine, 153(3), 137-146.

12. Ponomarenko I.V., Sukmanova I.A. (2019)Thrombosis risk factors and gene mutations in young age patients with acute coronary syndrome. Kardiologiia.;59(1S):19-24. (In Russ.)

13. Popov S.V., Garganeeva A.A., Borel K.N., Kuzheleva E.A., \&Okrugin S.A. (2016). Myocardial infarction in young patients: a long-term comparative analysis of developmental characteristics, clinical course and management strategy. Complex Issues of Cardiovascular Disease, 5 (4), 66-72.

14. Saleem, M., Durrani, A. K., Adeeb, M., \& Siddique, A. R. (2020). Psychosocial risk factors of cardiovascular disease in Pakistani adolescents and young adults: A Systematic Review. JPMA. The Journal of the Pakistan Medical Association, 70(9), 1601-1604.

15. Vasan, S. K., Antonisamy, B., Gowri, M., Selliah, H. Y., Geethanjali, F. S., Jebasingh, F. S., ... \& Osmond, C. (2020). Prevalence, incidence and predictors of cardiovascular risk factors: longitudinal data from rural and urban South India and comparison with global data. BMJ Open Diabetes Research and Care, 8(1), e001782. 